\title{
Setting Characteristics of Silicone-based Resilient Denture Liners
}

\author{
Koichi FUJII, Hiroyuki ARIKAWA, Takahito KANIE, Seiji BAN and Mitsuko INOUE \\ Department of Biomaterials Science, Field of Oral and Maxillofacial Rehabilitation, Course for Advanced Therapeutics, \\ Kagoshima University Graduate School of Medical and Dental Science, 8-35-1 Sakuragaoka, Kagoshima 890-8544, Japan \\ Corresponding author, E-mail:fuji@dentb.hal.kagoshima-u.ac.jp
}

Received July 13, 2004/Accepted October 27, 2004

\begin{abstract}
The aim of this study was to investigate the setting characteristics of seven silicone-based resilient denture liners during setting. Maximum extrusion force - at the flow rate of $1 \mathrm{~cm} / \mathrm{min}$ - ranged from 0.183 to $1.26 \mathrm{MPa}$. Working time and setting time ranged from 2.0 to 5.0 minutes and 1.9 to 6.8 minutes respectively. Consistency as described in JIS T6519-2000 was 32.4 to $46.5 \mathrm{~mm}$. As normal load of $1 \mathrm{kgf}$ was applied to a specimen held between two glass plates after mixing, the time at which film thickness reached up to $1 \mathrm{~mm}$ was 4.0 to 13.0 minutes at $23^{\circ} \mathrm{C}$ and 2.2 to 5.5 minutes at $37^{\circ} \mathrm{C}$. These results suggested that the reaction rate of materials used in this study differed from one brand to another. Against this backdrop of differing reaction rates amongst brands, it is therefore vital that a denture liner material's setting characteristics be carefully considered whenever it is used in clinical dentistry to prevent any undesirable or unexpected results and outcome.
\end{abstract}

Key words: Silicone-based resilient denture liner, Elastic recovery, Consistency

\section{INTRODUCTION}

Excessive resorption of alveolar bone and localized lesions of alveolar mucosa tend to develop in patients that wear denture for a long time. To solve these problems, soft denture liners have been often used because of their ability to relax and/or proportionate masticatory pressure on the supporting tissue, as well as to tighten denture retention by their viscoelastic properties ${ }^{1-3)}$. The materials used in clinical practice can be classified into three groups according to their chemical structure: acrylic, silicone, and fluoroethylene types; and also into different subgroups according to their curing type, such as chemical- and heat-cured types ${ }^{4,5)}$. Denture liners have several problems associated with their use before and after setting - namely varying degrees of fluidity and consistency, loss of softness, colonization by Candida albicans, porosity, poor tear strength, and deterioration of bonding strength to denture ${ }^{6,7)}$. Especially in cases of direct method such as cured-inmouth, these properties would become more prominent: degrees of fluidity and consistency, or working and setting times. Nevertheless, a few of such setting characteristics of denture liners have been reported ${ }^{5)}$, while bonding between resilient liner and denture base ${ }^{8-11)}$ or physical and mechanical properties of denture liners ${ }^{12-16)}$ have been examined by many investigators. Recently, new brands of silicone-based resilient denture liner have been placed on the market. Setting characteristics of these materials including new brands is essential for selection of the appropriate brand to the purpose of clinical usage and the individual dentist's technique.

The purpose of this study was to investigate the setting characteristics of four new silicone-based resilient denture liners and compare them against three established silicone liners, and thereby discuss the ease of handling of each material examined.

\section{MATERIALS AND METHODS}

\section{Materials}

Materials used in this study were listed in Table 1, together with the code, manufacturer, and lot number. The new materials were ET-N, ET-S, ZR-S, and ZR-SS. Mixing of cartridge-type materials was carried out using a dispenser (Cartridge dispenser II, GC, Tokyo, Japan) and tip (Mixing tip II, S(Pink), GC, Japan) according to manufacturer's instructions. All measurements were done three times.

\section{Extrusion force}

Maximum extrusion force and extrusion energy (i.e., cumulative work required for extruding) were determined when each material was auto-mixed in air at room temperature using the dispenser and tip ( $\mathrm{S}$ (Pink): inside diameter of tip end was $4.8 \mathrm{~mm}$ ) in a universal testing machine (Techno Graph TG-50kN, Minebea, Nagano, Japan). Cross-head speeds (i.e., flow rates of material) were 1,2 and $3 \mathrm{~cm} / \mathrm{min}$, and distance limit was $8 \mathrm{~mm}$ at which flow condition of each material contained a 4-mm distance that coincided with a maximum and constant extrusion force. Extrusion energy was obtained by calculating the area under the extrusion force-distance curve.

\section{Elastic recovery}

After mixing had started in air cabinet at $23 \pm 0.5$ or $37 \pm 0.5{ }^{\circ} \mathrm{C}$, elastic recovery was measured for 20 
Table 1 Materials used in this study

\begin{tabular}{|c|c|c|c|c|c|c|}
\hline \multirow{2}{*}{ Material } & \multirow{2}{*}{ Code } & \multirow{2}{*}{ Manufacturer } & \multirow{2}{*}{ Lot. No. } & \multirow{2}{*}{ Working time (s) } & \multicolumn{2}{|c|}{ Setting time $(\min )$} \\
\hline & & & & & Direct & Indirect \\
\hline EVATOUCH SUPER NORMAL & ET-N & $\mathrm{NEO}^{1}$ & ER37C I & $<90-120$ & $<5$ & $<30$ \\
\hline EVATOUCH SUPER SLOW & ET-S & $\mathrm{NEO}^{1}$ & ER38C I & $<120-180$ & $<6$ & $<30$ \\
\hline PERMAFIX-KOHLERR ${ }^{\circledR}$ & $\mathrm{PF}-\mathrm{K}$ & KOHLER $^{2}$ & 21102 & 60-105 & $5<$ & $30<$ \\
\hline RELINE Soft & RL-S & $\mathrm{GC}^{3}$ & 306031 & $<120$ & $5<$ & $30<$ \\
\hline SOFRELINER MS & SL-M & TOKUYAMA $^{4}$ & 691333 & $60-90$ & $5<$ & $20<$ \\
\hline ZEATY Reliner Soft & ZR-S & Panasonic-dental $^{5}$ & 402003 & $60-80$ & 3 & $4\left(35^{\circ} \mathrm{C}\right)$ \\
\hline ZEATY Reliner Super Soft & ZR-SS & Panasonic-dental $^{5}$ & 402004 & $90-120$ & 3 & $4\left(35^{\circ} \mathrm{C}\right)$ \\
\hline
\end{tabular}

${ }^{1}$ Neo Dental Chemical Products Co. Ltd., Tokyo, Japan

${ }^{2}$ Kohler Medizintechnik, Neuhausen, Germany

${ }^{3} \mathrm{GC}$ Corporation, Tokyo, Japan

${ }^{4}$ Tokuyama Dental Corp., Tokyo, Japan

${ }^{5}$ Panasonic-dental Co., Osaka, Japan

minutes using a pulsating rheometer designed by Arikawa et $a l^{17)}$. Elastic recovery (\%) was calculated using free elastic recovery obtained 2 seconds after a torsional strain of $20 \%$ had been applied for 0.2 seconds to the specimen $(25 \mathrm{~mm}$ in diameter $\times 1.6$ $\mathrm{mm}$ in height) and then removed. The median of three measurements was employed in Figs. 1 and 5.

\section{Working time and setting time}

Using the change of elastic recovery with time as mentioned above, working time was determined as the elapsed time from start of mixing to the time at which each material showed its first elastic recovery at $23 \pm 0.5^{\circ} \mathrm{C}$. Setting time was defined as the time when the magnitude of elastic recovery reached its maximum and constant value at $37 \pm 0.5^{\circ} \mathrm{C}^{17)}$.

\section{Consistency}

Consistency was determined by means of measurement described in JIS T6519-2000 ${ }^{18)}$, except that specimen of $2 \mathrm{~mL}$ held between two glass plates was placed at 60 seconds after start of mixing (versus the recommended 30 seconds) into an air cabinet at 37 $\pm 0.5^{\circ} \mathrm{C}$. In addition, film thickness of specimen which was held between two glass plates after setting - was measured using a vernier caliper (Digimatic, Mitutoyo, Kanagawa, Japan).

\section{Film thickness}

A specimen of $0.1 \mathrm{~mL}$ held between two glass plates was placed at 60 seconds after start of mixing into an air cabinet at $23 \pm 0.5$ or $37 \pm 0.5^{\circ} \mathrm{C}$. Thereafter a normal load of $1 \mathrm{kgf}$ was applied for 1 minute at regular time intervals from start of mixing. Film thickness was measured at 8 minutes after start of mixing, except for ET-S and obtained by subtracting the thickness of the two original glass plates from the entire thickness when the material was lying between the two glass plates.

Data were statistically analyzed using one-way analysis of variance and Fisher's Protected Least
Significant Difference test.

\section{RESULTS AND DISCUSSION}

Fig. 1 shows the typical extrusion force-distance curves of SL-M, which was extruded at cross-head specd of $2 \mathrm{~cm} / \mathrm{min}$. Figs. 2 and 3 show the maximum and constant extrusion force and the extrusion energy when seven silicone-based resilient denture liners were extruded from the cartridge of each material at rates of 10,20 , and $30 \mathrm{~mm} / \mathrm{min}$ with a distance limit of $8 \mathrm{~mm}$. In the case of $10 \mathrm{~mm} / \mathrm{min}$, the extrusion force of PF-K was the smallest $(0.183$ $\mathrm{MPa})$ whereas that of RL-S was the largest (1.26 $\mathrm{MPa})(\mathrm{p}<0.05)$. As the rate increased to $30 \mathrm{~mm} /$ $\mathrm{min}$, these values were increased by $61-115 \%$ compared to those of $10 \mathrm{~mm} / \mathrm{min}$. Therefore, increase in magnitude of extrusion force was not directly proportional to increase of extrusion rate, but rather at a decreasing rate. It can be seen that all materials

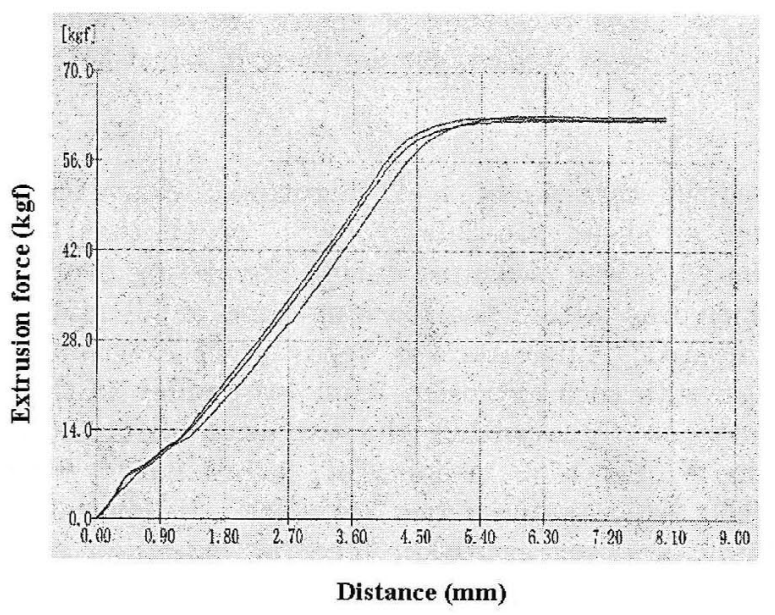

Fig. 1 Typical extrusion force-distance curves of three measurements obtained in air at $23^{\circ} \mathrm{C}$. Material used was SL-M and was extruded at a crosshead speed of $2 \mathrm{~cm} / \mathrm{min}$. 


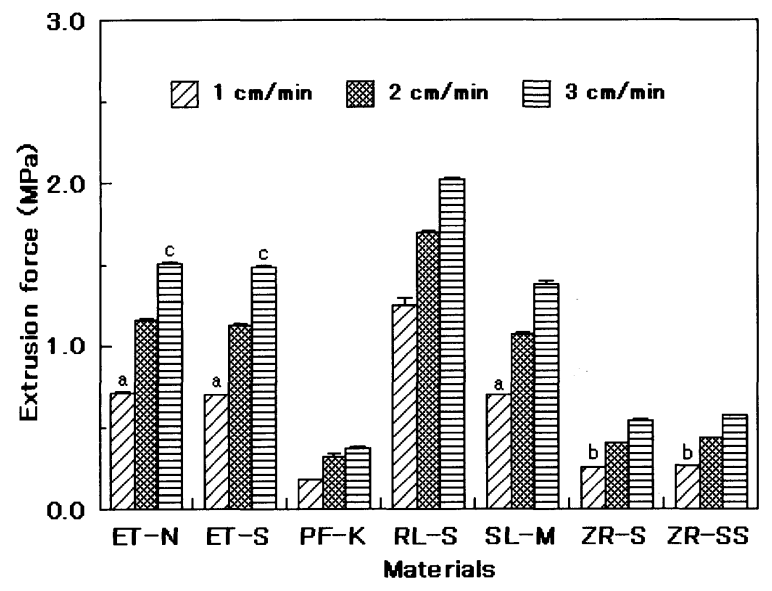

Fig. 2 Comparison of extrusion force ( $\mathrm{MPa})$ for seven silicone-based resilient denture liners. Same letter over columns denotes no significant differences among their values $(p>0.05)$.

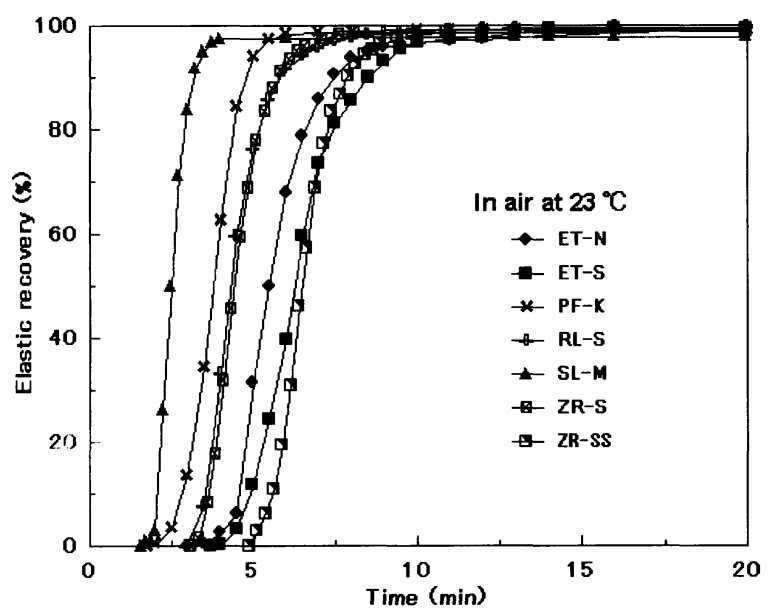

Fig. 4 Variation of elastic recovery with an elapsed time from start of mixing for seven siliconebased resilient denture liners in air at $23^{\circ} \mathrm{C}$.

used in this study had thixotropic characteristics such as shear-rate thixotropy ${ }^{19)}$, for all that extrusion force was measured during the setting process which was within the working time of all materials evaluated. Likewise, the behavior of extrusion energy with each extrusion rate was similar to that of extrusion force within the extrusion distance of 8 $\mathrm{mm}$ - hence a meaningful correlation $(\mathrm{r}=0.995$ 0.999) between these two variables. In clinical dentistry, a lower extrusion force or extrusion energy could be preferred from the standpoint of manipulation as it facilitates proper film spread of denture liner.

Variation of elastic recovery from start of mixing up to 20 minutes in air at 23 and $37^{\circ} \mathrm{C}$ is shown in Figs. 4 and 5. The measuring temperatures of 23

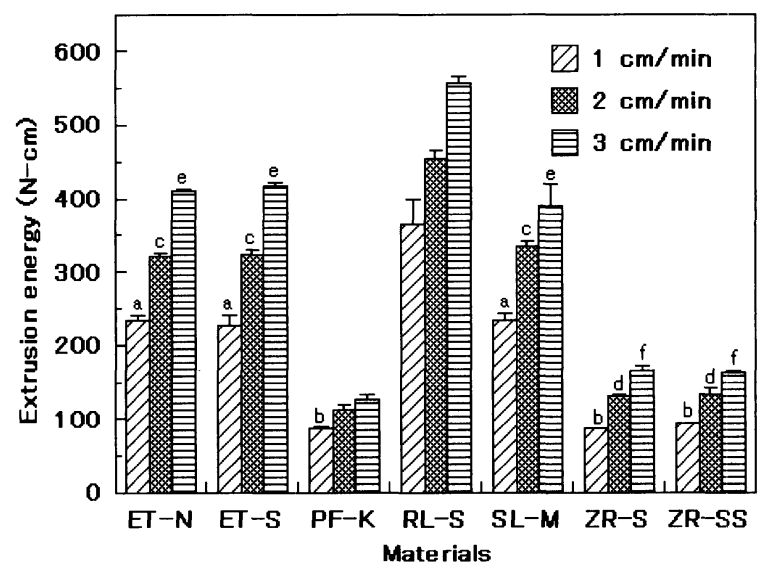

Fig. 3 Comparison of extrusion energy (N-cm) for seven silicone-based resilient denture liners. Same letter over columns denotes no significant differences among their values $(p>0.05)$.

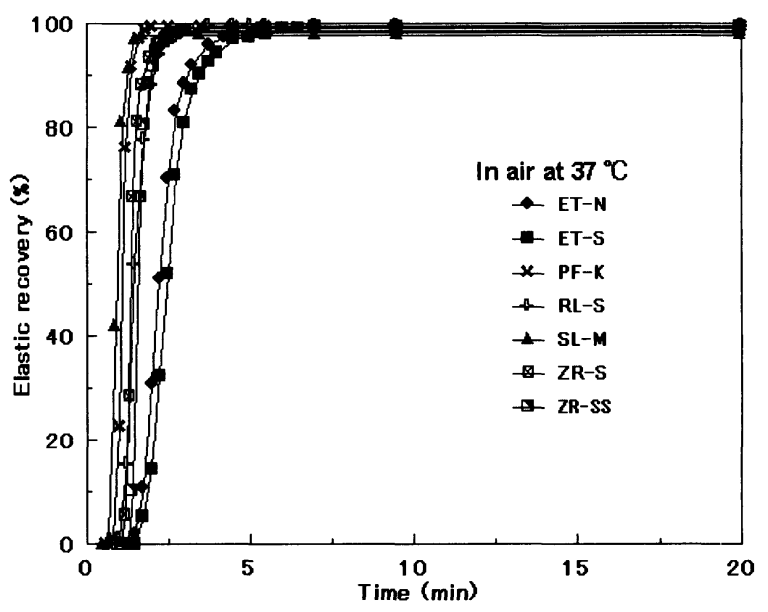

Fig. 5 Variation of elastic recovery with an elapsed time from start of mixing for seven siliconebased resilient denture liners in air at $37^{\circ} \mathrm{C}$.

and $37^{\circ} \mathrm{C}$ were selected, respectively, for investigation on direct method and indirect method. Using elastic recovery at $50 \%$ for convenient comparison, SL-M reached its $50 \%$ most quickly in air at $23^{\circ} \mathrm{C}$ whereas ET-S was the slowest. When measuring temperature increased from 23 to $37^{\circ} \mathrm{C}$, these elastic recovery times reduced by about $52-60 \%$. But, the ranking order of elastic recovery times among the materials remained the same as at $23^{\circ} \mathrm{C}$, except for ZR-SS. This implied that the rate of setting reaction for each material was dependent on temperature, as seen here when temperature was raised from 23 to $37^{\circ} \mathrm{C}$. In particular, it could be seen that the setting reaction of ZR-SS was remarkably influenced by temperature rise. At $23{ }^{\circ} \mathrm{C}$, ZR-SS was the slowest material of elastice recovery; but at $37^{\circ} \mathrm{C}$, it was 
ranked 5th among the seven materials. In other words, as the temperature increased, the time with which ZR-SS took for elastic recovery was reduced by $70 \%$.

Working and setting times determined from elastic recovery were 2.0-5.0 minutes and 1.9-6.8 minutes respectively (Fig.6). While working times in the current study were 1.4-2.5 times longer than those given in manufacturers' instructions (Table 1), the setting times were conversely 0.37-1.0 times shorter with the exception of ET-N and ET-S. The setting times of ET-N and ET-S were 1.1 times longer in the current study. These results suggested that working and setting times from the standpoint of elastic recovery differed a little from those given in manufacturers' instructions - although the latter should be intended to be the most efficient criteria in clinical dentistry. It seemed that this difference in working and setting times stemmed from the measuring techniques used for evaluation. In general, PF$\mathrm{K}$ and SL-M - which possessed a shorter setting time in this study - would perhaps mean shorter consultation hours per patient. But working time or time for muscle trimming might not be enough to the required time of attaining their object. In addition, ET-N and ET-S might be materials that are useful for annulment of the demerit (with PF-K and SL-M) since they had longer setting time themselves.

As shown in Fig. 7, consistency of each material was ranked between 32.4 and $46.5 \mathrm{~mm}$, where ET-S was the most fluid. ET-N, SL-M, and ZR-SS had similar values and were a little lower than ET-S $(p<0.05)$. For the other materials, their fluidity ranked in this order: PF-K $>$ RL-S $>$ ZR-S. In order to determine consistency in this study, each material was placed into air cabinet at $37^{\circ} \mathrm{C}$ at $1 \mathrm{~min}$ ute after start of mixing - although the time was given as 30 seconds in JIS T6519. This was because 30 seconds was not enough time for manipulation. Therefore, it might be necessary to amend the 30 second time described in JIS T6519. On the other hand, film thickness yielded a lower value when material possessed larger consistency, and an adequate correlation $(r=-0.99)$ was estimated between both variables. The relationship among consistency, setting time, and film thickness was shown in Fig. 8. The coefficient of correlation between consistency and setting time was a low value of $\mathrm{r}=0.44$, indicating that their correlation might be inadequate. It could be inferred that low fluidity (as deduced from the correspondingly low extrusion force shown in Fig. 2) would influence consistency more significantly, rather than the magnitude of setting time.

Figs. 9 and 10 show the variation of film thickness with time after start of mixing for seven materials measured in air cabinet at 23 and $37^{\circ} \mathrm{C}$ respectively. The time at which $1-\mathrm{mm}$ film thickness was produced ranged from 4.0 to 13.0 minutes at

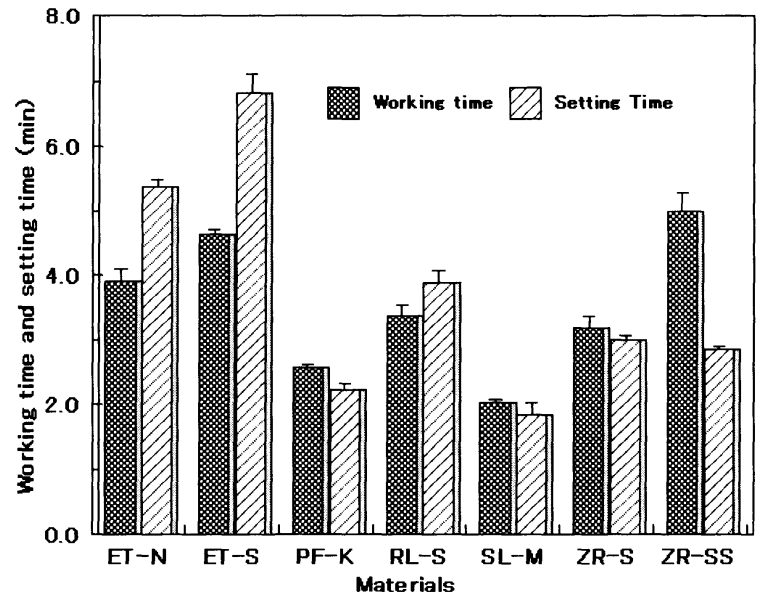

Fig. 6 Working time and setting time of seven silicone-based resilient denture liners. Each time denotes a significant difference among their values of all materials used $(\mathrm{p}<0.05)$.

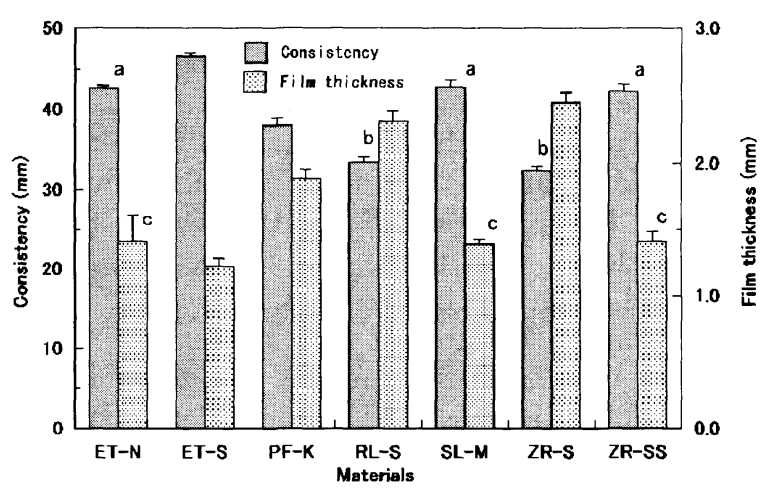

Fig. 7 Consistency of seven silicone-based resilient denture liners. Same letter over columns denotes no significant differences among their values $(\mathrm{p}>0.05)$.

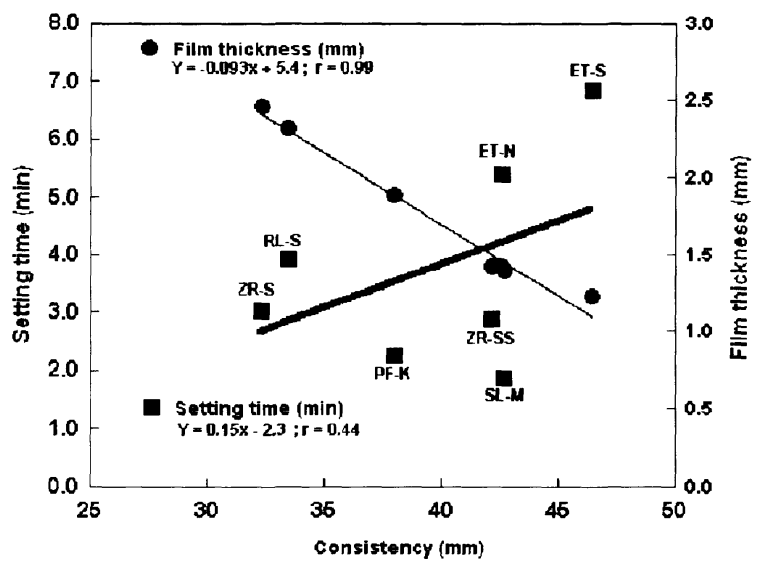

Fig. 8 Relationship of consistency, setting time, and film thickness. 


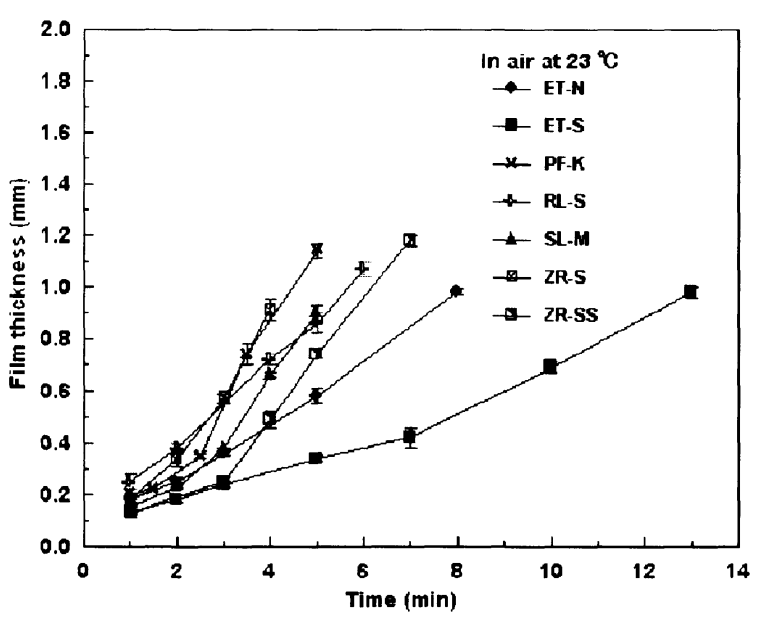

Fig. 9 Variation of film thickness with an elapsed time from start of mixing for seven siliconebased resilient denture liners in air at $23^{\circ} \mathrm{C}$.

$23^{\circ} \mathrm{C}$ and 2.2 to 5.5 minutes at $37^{\circ} \mathrm{C}$. These results implied that reaction rate or its dependence upon temperature differed among the materials used. In fact, these results might be further utilized as tentative criteria against time for forming $1-\mathrm{mm}$ film thickness. For ET-N and ET-S, the setting reaction proceeded slowly with time. For the rest of the materials used, their setting reactions developed rapidly between 2 and 3 minutes at $23^{\circ} \mathrm{C}$ or between 1.5 and 2 minutes at $37^{\circ} \mathrm{C}$, hence causing a marked increase in their film thickness. In clinical dentistry, it is considered that if a liner mixture (paste) is more fluid, then manipulation would be easier as the paste can be spread easily on the palate side of a denture, although film thickness would be compromised that is reduced. At the same time, the mixture should also have proper fluidity so as not to fall out of a denture.

For the materials used in this study, the results obtained differed from one product to another. It could be seen that the favorable properties required of denture liner could not be satisfied by one material only. Therefore, the results suggested that in clinical dentistry, the setting characteristics of each material should be considered because the reaction rate and/or fluidity during setting differed among the seven silicone-based resilient denture liners.

\section{ACKNOWLEDGEMENTS}

The authors would like to thank NEO Dental Chemical Products Co. and Panasonic dental Co. for generously providing the materials used in this study.

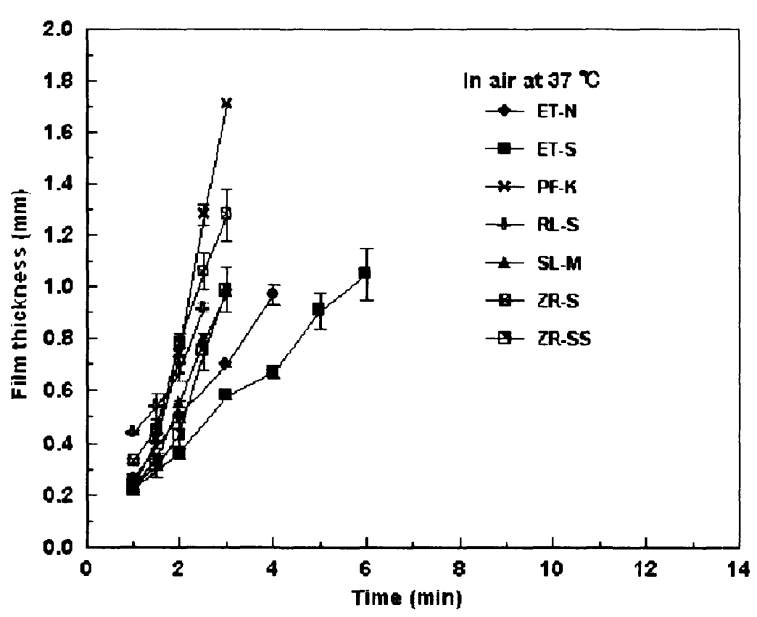

Fig. 10 Variation of film thickness with an elapsed time from start of mixing for seven siliconebased resilient denture liners in air at $37^{\circ} \mathrm{C}$.

\section{REFERENCES}

1) Murata H, Taguchi N, Hamada T, McCabe JF. Dynamic viscoelastic properties and the age changes of long-term soft denture liners. Biomaterials 2000; 21: 1421-1427.

2) Murata H, Taguchi N, Hamada T, Kawamura M, McCabe JF. Dynamic viscoelasticity of soft liners and masticatory function. J Dent Res 2002; 81: 123-128.

3) Kawano F, Ohguri T, Koran A, Matsumoto N, Ichikawa $\mathrm{T}$. Influence of lining design of three processed soft denture liners on cushioning effect. J Oral Rehabil 1999; 26: 962-968.

4) Braden M, Wright PS, Parker S. Soft lining materials: A review. Eur J Prosthodont Restor Dent 1995; 3: 163174.

5) McCabe JF. A polyvinylsiloxane denture soft lining material. J Dent 1998; 26: 521-526.

6) Sekine H. Illustrated encyclopedia and dictionary of dental science, 1st ed, Ishiyaku Publishers, Tokyo, 1989, p.1701.

7) Kulak-Ozkan Y, Sertgoz A, Gedik H. Effect of thermocycling on tensile bond strength of six siliconebased, resilient denture liners. J Prosthet Dent 2003; 89: 303-310.

8) Aydin AK, Terzioglu H, Akinay AE, Ulubayram $\mathrm{K}$, Hasirci N. Bond strength and failure analysis of lining materials to denture resin. Dent Mater 1999; 15: 211218.

9) Sertgöz A, Kulak Y, Gedik H, Taskonak B. The effect of thermocycling on peel strength of six soft lining materials. J Oral Rehabil 2002; 29: 583-587.

10) Al-Athel M, Jagger R, Jagger D. Effect of aging on the bond strength of a permanent denture soft lining material. J Oral Rehabil 2002; 10: 992-996.

11) Hong G, Murata $H$, Hamada $T$. Relationship between plasticizer content and tensile bond strength of soft denture liners to a denture base resin. Dent Mater J 
2004; 23: 94-99.

12) Waters $M$, Jagger $R$. Improved wettability of an experimental silicone rubber denture soft lining material. J Biomed Mater Res 1999; 48: 765-771.

13) Waters $M$, Jagger $R$. Mechanical properties of an experimental denture soft lining material. J Dent 1999; 27: 197-202.

14) Gregory P, Frederick R. In vitro hardness, water sorption, and resin solubility of laboratory-processed and autopolymerized long-term resilient denture liners over one year of water storage. J Prosthet Dent 2002; 88: 139-144.

15) Muraoka G, Takahashi H, Hayakawa I. Effects of cyclic loading on viscoelastic properties of soft lining materials. Dent Mater J 2003; 22: 251-261.

16) Dìnçkal Yanikoglu N, Denizoglu S. An investigation of the tear energy of five soft lining materials. Dent Mater J 2003; 22: 444-451.

17) Arikawa $H$, Fujii $K$, Kanie $T$, Joshin $K$, Inoue $K$, Onizuka T, Jimi T. A method for the determination of setting characteristics of elastomeric impression materials. Dent Mater J 1982; 1: 67-72.

18) Japanese Industrial Standard. Short term resilient lining materials for removable dentures. JIS T 6519-2000.

19) Nakagawa T. Rheology, 2nd ed, Iwanami Zensyo, Tokyo, 1978, p.103-105. 